\title{
Today's Cake is a Log: Remediating the Intermediality of Hotel Pro Forma's Works in an Exhibition
}

Daria Skjoldager-Nielsen and Kim Skjoldager-Nielsen

\begin{abstract}
This article explores intermediality not only as an aesthetic strategy for theatre itself, but also regarding how this strategy can be remediated and applied to another medium: a performative exhibition. The case explored here is the Danish performance theatre company Hotel Pro Forma and their exhibition Today's Cake is a Log (2015), produced for the company's thirtieth anniversary. We argue that the exhibition remediates the company's aesthetical strategy in such a way that it transforms the theatre spectator into a performer, who thereby embodies and assimilates the theatre's aesthetic strategy through performative acts during the visit to the exhibition. The analysis is contextualized: first, by a presentation of intermediality theory developed for theatre and performance; second, by an introduction of Hotel Pro Forma, its artistic project and intermedial aesthetics exemplified through staging devices and performances. Finally the analysis of the performance exhibition through the experience of the visitor is presented.
\end{abstract}

In this article we explore intermediality not only as an aesthetic strategy for theatre, but also how the aesthetics of theatrical performance, its formal performative logics, may be remediated in order to reflect the original work in an exhibition. Our point of departure is intermediality as it is conceptualized for the theatre.

How to cite this book chapter:

Skjoldager-Nielsen, Daria, and Kim Skjoldager-Nielsen. “Today's Cake is a Log: Remediating the Intermediality of Hotel Pro Forma's Works in an Exhibition." In The Power of the In-Between: Intermediality as a Tool for Aesthetic Analysis and Critical Reflection, edited by Sonya Petersson, Christer Johansson, Magdalena Holdar, and Sara Callahan, I49-г 8г. Stockholm: Stockholm University Press, 20I8. DOI: https://doi.org/Io.I6993/baq.g. License: CC-BY. 
Yet our understanding of performance is also inscribed in the broad-spectrum approach of performance studies, as we extend the intermediality concept to include stagings and performances noncompliant with traditional concepts of theatre. ${ }^{\text {I This approach }}$ allows us to extend performance analysis to include exhibitions, where the visit may be seen as a performance executed by the attendee-ideally the visitor's realization of the curator's staging or arrangement of exhibits. ${ }^{2}$

As we intend to show, the extended approach to our analytical example is particularly appropriate since it connects the theatre to the exhibition as a locus for literally "(re)visiting" the aesthetics of the theatre company put on display. We pursue the question of how the exhibition may be seen as a remediation of the intermedial strategy found in Hotel Pro Forma's stage works. We propose that the exhibition remediates this aesthetical strategy in a way that transforms the theatre spectator into a performer, who may then embody and assimilate the aesthetic strategy through her performative acts. Here we understand "remediation" in the sense Jay David Bolter and Richard Grusin suggest: as an appropriation of "the techniques, forms, and social significance of other media to [...] refashion them in the name of the real." 3 This remediation may be seen as an alternative to theatre exhibitions that

I Richard Schechner, "Performance Studies: The Broad Spectrum Approach," in The Performance Studies Reader, ed. Henry Bial (New York: Routledge, 2004), 7-9.

2 Of course, the curator's intentions may not always be realized by the visitor. For a discussion of audience behaviors in exhibitions, see Bruno Ingemann, "Den besøgende: Social identitet, læring og oplevelse - en metodisk diskussion," in Udstillinger mellem focus \& flimmer, eds. Elisabeth Bodin and Johanna Lassenius (Copenhagen: Multivers, 2006). For a discussion of the exhibition as the curator's indirect staging of the visitor's acts in the exhibition space, see Mieke Bal, "Curatorial Acts," Journal of Curatorial Studies, vol. I, no. 2 (2012): I79-I92.

3 We do not, however, subscribe to Bolter and Grusin's claim that all mediation is remediation; it is rather to be considered a creative strategy, as suggested by the theatre scholar Erik Exe Christoffersen. Cf. Jay David Bolter and Richard Grusin, Remediation: Understanding New Media, (Cambridge: MIT Press, I999), 65; Peripeti, "Remediering mellem film og teater - en kreativ strategi," accessed April I2, 20I7, http://www. peripeti.dk/ 2009/06/03/265/. 
take a less performative approach to the visitor and remain based on conventional displays and informative documentation of stage artefacts. ${ }^{4}$

Our example is the exhibition Today's Cake is a Log (Dagens kage er en trostamme) by the Danish performance theatre company Hotel Pro Forma. The exhibition was shown at the arts venue Gamle Strand in Copenhagen November 6-29, 2015. The exhibition was produced for Hotel Pro Forma's thirtieth anniversary and it was curated by Kirsten Dehlholm, who has served as the artistic director of the company since its establishment in I985. Given the occasion, the exhibition was a retrospective of the works by Hotel Pro Forma, assembling a selection of artefacts and photo and video material from the company's total of more than fifty large and small productions. Moreover, it staged all in all 130 hours of readings of texts originally used in the performances. ${ }^{5}$ Contrary to what one might have expected, this jubilee exhibition did not provide the visitor with a documentary and chronological overview of Hotel Pro Forma's works and history; rather it attempted to facilitate a sensorial, experiential insight into the aesthetic strategy of the company. This emphasis on the

4 To be fair, many theatre museums and museums presenting theatre are following the general curatorial trend of experimenting with different formats and strategies of intermediality in the communication with the visitors. A recent instance of this is the exhibition Curtain Up: Celebrating 40 Years of Theatre in London and New York, which ran at the Victoria \& Albert Museum in London between February 9 and August 3I, 2016. Stage designer Tom Piper and RFK Architects created an exhibition environment that allowed the visitor to immerse herself into the different phases of theatre production through evocative set designs, audio-visual displays, and stage artefacts, representing a selection of historically significant performances from the two cities. "Curtain Up: Celebrating 40 Years of Theatre in London and New York," V\&A, accessed April I2, 20I7, https://www.vam.ac.uk/exhibitions/ curtain-up-celebrating-40-years-of-theatre-in-london-and-new-york.

5 For an introduction to Hotel Pro Forma, see Erik Exe Christoffersen and Kathrine Winkelhorn, eds., Skønhedens Hotel: Hotel Pro Forma: Et laboratorium for scenekunst (Aarhus: Aarhus Universitetforlag, 20I5); (in English) Per Theil, Kirsten Dehlholm, and Lars Qvortrup, Hotel Pro Forma: The Double Staging: Space and Performance (Copenhagen: Arkitektens Forlag, 2003). 
visitor's experience is why we find the performance approach rewarding in understanding the exhibition's remediation of the theatrical works.

Before we begin analyzing the exhibition we will provide a context. First, we present how we understand the topic of intermediality from a theatre and performance studies perspective, building on a complex of what we see as closely interconnected concepts: hypermediality, intermediality, intermedial experience, performance of perception, and performativity of perception. ${ }^{6}$ Besides being our theoretical foundation, the overview contributes to the overall introduction and discussion of intermediality in this anthology. Second, we introduce Hotel Pro Forma, its artistic project and intermedial aesthetics exemplified through staging devices and performances. While the theoretical concepts provide our analytical apparatus, the aesthetic strategy of Hotel Pro Forma supplies the necessary backdrop for understanding the remediation of its theatrical works into the exhibition.

\section{Hyper- and Intermediality in Theatre and Performance}

How does intermediality come about? And what does it mean? We assume theatre is a hypermedium that includes all other media as well as the co-present bodies of performers and spectators. As we unpack this assumption it will become clear that hypermediality in theatre is the very basis for its intermediality. The live performer functions as the interconnector between media, and, in turn, between the intermedial stage and the spectator, who ultimately realizes intermediality as experience. Understanding this hyper- and intermediality of theatrical performance is important for our analysis. In the case of Today's Cake is a Log, the live performances are remediated through exhibited artefacts, and we propose that the exhibition as remediation allows the visitor to

${ }^{6}$ We mainly draw on articles from the seminal works on theatre and intermediality: Freda Chapple and Chiel Kattenbelt, eds., Intermediality in Theatre and Performance (Amsterdam and New York: Rodopi, 2006); Sarah Bay-Cheng, Chiel Kattenbelt, Andy Lavender, and Robin Nelson, eds., Mapping Intermediality in Performance (Amsterdam: Amsterdam University Press, 2010). 
become that interconnector of media, thereby experiencing the intermedial strategy of Hotel Pro Forma through the exhibition.

Chiel Kattenbelt explains hypermediality in the theatre simply as its capacity "to incorporate all other arts and media." $7 \mathrm{He}$ elaborates on this concept and points to the fact that theatre's all-inclusiveness towards other art forms and media is founded on it being physical and not virtual. ${ }^{8}$ The grounding of theatre in physical space provides a platform where the other arts and media can be staged, or more precisely, become components in the communicative process of a theatrical event, which unfolds here and now in the co-presence of performers and spectators. The spectator perceptually connects to the performer as "the player of the different media who acts in the empty spaces between the media." 9 From the point of view of the spectator, the different media simultaneously retain their own immediately perceivable functions, for example, through the screening of live video or video recordings (pre-recorded), or live imagery (zoom-ins on performers and stage action, etc.), and they undergo a transformation into theatrical signs, that is, signs of signs, to be interpreted in accordance with the dramaturgy and the context of the given performance. Of course, these acts of interconnecting different media may vary depending on the character of the staging, for example, from subtly suggesting connections to the spectator (who perceives and interpret them) to letting the performer physically enact them on stage (practically operating technological devices). But interconnecting media, as Kattenbelt hints at, may also simply mean that

7 Chiel Kattenbelt, "Theatre as the Art of the Performer and the Stage of Intermediality," in Intermediality in Theatre and Performance, edited by Freda Chapple and Chiel Kattenbelt (Amsterdam and New York: Rodopi, 2006), 32.

8 According to Meike Wagner, theatre as a hypermedium becomes " a compromise, which opens up possibilities of connecting to the ancient art form of theatre with contemporary notions of media, without renouncing the claim of corporeal presence in live performance.” Meike Wagner, "Of other Bodies: The Intermedial Gaze in Theatre," in Chapple and Kattenbelt, Intermediality, I 27. See also Chiel Kattenbelt, "Intermediality in Theatre and Performance: Definitions, Perceptions and Medial Relationships," Culture, Language and Representation, vol. VI (2008): 23.

9 Kattenbelt, "Intermediality in Theatre and Performance," 23. 
the performer, through her physical artistic acts, combines the medialities of art forms that make up the theatre performance (articulation of words-drama/literature; modulation of voiceopera/music; gesticulation of the body-dance/visual arts), and in doing so provides mediation through her own capacity of physical presence. ${ }^{\mathrm{IO}}$ In this context, it is suggested that in theatre and performance intermediality basically conceptualizes "the process of how something that appears fixed becomes different." II This process does not limit itself to the level of the performer; it also takes place on the macro level of performance, that is, in-between types of theatre such as "literary theatre," "music theatre," and "visual theatre," of which each has its own dominant sign system of "word," "sound," and "image." I2 Thus, it becomes evident when it produces hybrid notions, for instance, "visual opera" oras in our case-a merging of performance and exhibition.

\section{Intermedial Experience (in Post-Dramatic Theatre) and How to Analyze It}

We assume that the incorporation of different media in theatre qualifies intermediality as an inherent and therefore ever-present structural feature of theatre, employing the medialities of space, time, image, body, voice, gesture, music, lights, text, costumes, props, and set design. What is of particular interest to the conceptual discussion in this book, however, is that intermediality-in its capacity of media interplay-may be utilized in the staging of a performance as an aesthetic strategy. That is, certain philosophical or political aspirations reflect upon and affect the way we as humans relate to our surroundings, our lifeworld, society, media realities-in particular, how we conceive of different phenomena and epistemological categories. ${ }^{\mathrm{I}}{ }^{3}$ Intermediality as aesthetic strategy aims at creating a certain experience for the spectator, which

ro See Kattenbelt's circular model representing theatre as the art of the performer in Kattenbelt, "Theatre as the Art of the Performer," 33.

I Chapple and Kattenbelt, Intermediality, I 2.

I2 Chapple and Kattenbelt, Intermediality, 2 I.

I3 Chapple and Kattenbelt, Intermediality, 24. 
we will exemplify later in the introduction to Hotel Pro Forma. We are interested in the notion of an intermedial experience, in order to employ it in our analysis. Lisbeth Groot Nibbelink and Sigrid Merx have made an attempt to conceptualize the typical experience and develop it into a pedagogical and analytical strategy that we find useful.

Following Kattenbelt, Nibbelink and Merx summarise intermediality as "performance and performative practices in which media not only exist next to each other, but through their interplay result in both a redefinition of media and resensibilisation of the senses." ${ }^{14}$ They relate the intermedial experience to the way "intermedial performance often plays with or explicitly deconstructs perceptual expectations and produces sensations ranging from subtle experiences of surprise or confusion, to more uncanny experiences of dislocation, displacement or alienation." Is These are effects that are known to occur with so-called postdramatic theatre, wherein the different media or medialities of the performance are organized not in accordance with the principle of bypotaxis, subordination, as one would find in dramatic theatre, where all other media support the text and the narrative, but following the principle of parataxis, non-hierarchy. This nonhierarchical ordering of media means they are juxtaposed and operate simultaneously on an equal level as to deliberately challenge the spectator's perception: ${ }^{16}$

Intermediality in the live performance calls for an active attitude on the part of the spectator that Lehmann describes as "evenly hovering attention" [...]. The spectator has to negotiate the perceptual experiences evoked by the various, simultaneous media relationships. [...] To experience intermediality therefore is an active embodied process of negotiating and shifting between different and conflicting medial realities, moving in and out of perceptual worlds, relating different impressions and signs, looking

${ }^{14}$ Lisbeth Groot Nibbelink and Sigrid Merx, "Presence and Perception: Analysing Intermediality in Performance," in Mapping Intermediality, 2 I 8.

is Nibbelink and Merx, "Presence and Perception," I I 9.

${ }^{16}$ Cf. Hans-Thies Lehmann, Postdramatic Theatre, trans. Karen JürsMunby (London and New York: Routledge, 2006), 86-88. 
for a point of connection that might integrate the confusing and disturbing sensations in a meaningful whole, however unstable and ephemeral this whole may be. ${ }^{17}$

The spectator embodies this process of intermedial experience, and the embodiment has consequences for the analytical approach, as "the intermedial is to be found as much in the structuring of the performance itself, where it manifests itself not as an experience, but as the interplay between different media." ${ }^{18}$ As Nibbelink and Merx conclude on the method, "[1] ocating the intermedial both in the body and in the performance requires a perceptual as well as a cognitive awareness." " 9

Nibbelink and Merx suggest a spectator/analyst who is intimately part of the production of intermediality, and who needs to be aware of her own participation. To further grasp how the intermedial experience unfolds, we find it necessary to distinguish between perceptual cause, performance (the staged as well as the perceived event), and perceptual effect, performativity (referring to the event's impact upon the one engaged in perception). In doing so, we first refer to Maaike Bleeker's concept "performance of perception," which connects the theatre performance to the spectator. ${ }^{20}$ In her example, the performance still plays itself out before the spectator at a certain distance but the structure of the performance is transmutable to the patterns of the spectator's perception. ${ }^{21}$ Hence, in theatre we may think of the spectator as someone who enacts or performs her perception as a bodily performance, which in effect is a reflection of a stage performance.

7 Nibbelink and Merx, "Presence and Perception," 220.

8 Nibbelink and Merx, "Presence and Perception," 220.

I9 Nibbelink and Merx, "Presence and Perception," 220.

${ }^{2 \circ}$ Maaike Bleeker, "Corporeal Literacy: New Modes of Embodied Interaction in Digital Culture," in Mapping Intermediality, 38.

${ }^{21}$ Bleeker draws attention to the work of the philosopher Alva Noë, who contends that perception is a mode of action, which not only engages the brain but the whole organism, and that it is an acquired skill. We actively engage in our surroundings through a number of perceptual systems at once, sight, hearing, smelling, touch, proprioception and kinesthesis, and a complete experience of the visible, audible, and tangible environment is created. Alva Noë, Action in Perception (Cambridge: MIT Press, 2004), 2. 
As it will become evident in our analysis of Hotel Pro Forma's exhibition, the bodily performance of perception is radicalized as the seated theatre spectator is transformed into a moving visitor, engaging with the staged environment of the exhibition instead of a performance on a stage.

Bleeker establishes that both bodily and staged performance of perception are culturally determined but also mutable. ${ }^{22}$ This concern with the effects of perception leads Bleeker to introduce her second concept, "performativity of perception": "the intermedial character of the theatre may [...] be used to undermine seemingly self-evident modes of perceiving and to draw attention to the performativity of perception: how perception actually produces what appears as the object of our perception." ${ }_{23}$ Kattenbelt, who also concerns himself with "the performativity of intermediality," offers a clarification to what end such a realization about perception in intermedial theatre may serve: "Aesthetic action (in production as well as perception) may be considered a form of exploration and reflection, which reinforces the communicative competence of socialized individuals." ${ }^{24}$ Localizing the performativity of perception, Kattenbelt points to the process of the theatrical event, which is not only self-referencing and self-reflecting by itself, but also effectuating similar attitudes of the perceiver who takes the position of the spectator: ${ }^{25}$ by watching theatre one becomes aware of oneself watching, and in the end, possibly, of what the process may have effectuated. As we shall see in our analysis of Hotel Pro Forma's exhibition, the performativity of perception may become even more conspicuous to the visitor, who physically enters into the exhibition environment, as cause-performance of perception-and effect-performativity of perception-are closer connected in the self-referential and self-reflexive process of the visitor.

${ }_{22}$ Bleeker, "Corporeal Literacy," 38.

${ }_{23}$ Bleeker, "Corporeal Literacy," 38.

${ }^{24}$ Chiel Kattenbelt, "Intermediality in Performance and as a Mode of Performativity," in Mapping Intermediality, 34.

${ }_{25}$ Kattenbelt, "Intermediality in Performance and as a Mode of Performativity," 32. 


\section{Introducing Hotel Pro Forma}

Kattenbelt's concept of intermediality as an aesthetic strategy that develops the audience's sensibility towards the construction of reality, through the bringing together and interplay of different media and medialities on the stage, seems particularly interesting in relation to Hotel Pro Forma's artistic project. In the following, we will give a brief introduction to Hotel Pro Forma's aesthetics and connect it with intermediality by looking into the staging devices employed in their productions. This will then serve as the backdrop for observing the transferal of the aesthetic strategy from stage performance to exhibition.

From the point of view of mainstream, realistic theatre, Hotel Pro Forma (established I985) is vastly unconventional as it negates all that mainstream theatre represents. The performances are non-dramatic, non-linear, and non-narrative in structure and content. The performers do not employ psychological acting. Instead, the performances are located in the in-between where they constantly contest and redefine what theatre is, through highly conceptual stagings that follow visual-musical scores, often staged in found non-theatre spaces. Actions and scenarios are organized and proceed in accordance with principles and systems that stem from, for example, mathematics, mythology, philosophy, encyclopedia, or the Internet's hypertext. In terms of idiom, Hotel Pro Forma draws on a variety of art forms and formats of staging (visual arts, installation, performance art, appropriation art, pop art, exhibition, opera, dance, musical, theatre, ritual, lecture, multimedia, etc.), as well as art historical movements (modernism, the historical avant-gardes, formalism, minimalism, concretism, etc.). Especially the formalist inspiration seems predominant in the way Hotel Pro Forma challenges our pre-understanding of the theatre and the world. ${ }^{26}$ Similar to Victor Shklovsky's defamiliarization or ostranenie, ${ }^{27}$ this is a staging of the spectator's sensation and

${ }^{26}$ Erik Exe Christoffersen, "Den u-selvfølgelige sansning," in Skønhedens Hotel: Hotel Pro Forma: Et laboratorium for scenekunst, eds. Erik Exe Christoffersen and Kathrine Winkelhorn (Aarhus: Aarhus Universitetsforlag, 20I 5 ).

${ }^{27}$ Lawrence Crawford, "Viktor Shklovskij: Différance in Defamiliarization," Comparative Literature 36 (I984): I6. 
perception, whose habitual or automatic unfolding is obstructed or disturbed by the staging in an effort to make her take a fresh look at the world. Ultimately, it is the creation of a state where all sorts of phenomena, freed from their conventional context, momentarily will appear in their splendid presence and beauty and rouse curiosity and thought. Hotel Pro Forma's project is a phenomenological one, which basically examines how phenomena appear to our consciousness. But it is also a project critical of the self-evident or intuitive ways with which we relate to our world. Thus, Hotel Pro Forma's project can be understood as emancipatory, reclaiming sensuality as a tool for becoming aware of the world; that is, an approach that not just surrenders to the sensual, but is reflective and thereby discovers new perspectives on already known phenomena.

Hotel Pro Forma has been compared to a laboratory. ${ }^{28}$ The investigations that take place as part of the artistic work are not scientific studies in which a hypothesis can be falsified or validated according to truth. On the contrary, they are aesthetic studies that call for decisions based on aesthetic judgment, that is, whether something within the frame of the staging concept is a valid or an invalid expression; whether it works or not. Hotel Pro Forma's process is similar to the operation of a scientific laboratory in that their aesthetic study is subject to systematized development, resulting in new performances, which in turn provides new knowledge about the world. As the director Kirsten Dehlholm puts it: "We are investigating the world and the performance is the investigation. We use the production to make 'a journey' into the world and come back with new knowledge and awareness. This should be clear to the audience, so they become involved in this study." ${ }^{29}$

According to Lars Qvortrup, the aesthetic investigations may be systematized by a categorization through which they unfold in the performances on three different levels (often simultaneously): I) studies questioning epistemological categories such as space,

${ }^{28}$ Lars Qvortrup, "Hotel Pro Forma: Laboratorium for æstetiske undersøgelser," Peripeti 25 (2016). See also Katherine Winkelhorn, "Et blik ind i Hotel Pro Formas kunstneriske praksis," in Skønhedens Hotel, 224-225.

29 Cited from Christoffersen, "Den u-selvfølgelige sansning," 25 . Translation by the authors. 
time, and transcendence, as a basic research of cognitive forms; 2) studies on a number of fundamental phenomena that exist in society, for example war, religion, and education; and 3) studies and challenges of a number of established artistic genres, including text-based theatre, exhibitions, and opera, which serve the development of the performing arts and their conditions, often resulting in hybrids such as visual opera or performative exhibitions. ${ }^{30}$

Just as the premises for a scientific laboratory experiment are known through the experimental setup or design, the constituents of staging are evident to the spectators of a Hotel Pro Forma performance. The performance does not seek to disguise its staging as the naturalistic or realistic theatre attempted through the creation of illusion, as in the drawing-room dramas of Ibsen and Strindberg; instead it exhibits the devices of staging in a way similar to post-dramatic theatre. ${ }^{3 \mathrm{I}}$ This blatantly self-referring strategy makes it possible for the spectator to observe the very process of the staging itself as it unfolds in the performance. By installing "an observer, who not just observe the world (as it 'is') but who watches his own observations of the world" our so-called "natural" or self-evident view of objects, that is, a first-order observation is challenged "implying that it could also be observed differently." ${ }^{2}$ Through the staging, the spectator makes what is called "a second-order observation." ${ }_{33}$ In this sense the performance becomes a medium for the spectator's self-observation and recognition of the premises for the performance's conception of reality. Qvortrup suggests that second-order observation applies as Hotel Pro Forma's aesthetic strategy as it creates "counter-intuitive images of epistemological categories as well as fundamental phenomena and artistic genres." 34

It is interesting that the second-order observation bears resemblance to the self-reflexivity pointed out by Kattenbelt as a characteristic of the theatrical performance process, and which

3० Qvortrup, "Hotel Pro Forma,” 87.

${ }^{31}$ Hans-Thies Lehmann includes Hotel Pro Forma in his list of post-dramatic theatre, see Lehmann, Postdramatic Theatre, 24.

32 Qvortrup, "Hotel Pro Forma," 9I-92.

33 Qvortrup, "Hotel Pro Forma," 9I-92.

34 Qvortrup, "Hotel Pro Forma," 9I-92. 
is highlighted in contemporary post-dramatic, intermedial theatre. Therefore, we suggest that second-order observation is the perceptual operation the spectator performs in the realization of intermediality, as in Nibbelink and Merx's localization of intermediality in the spectator's body, and Bleeker's concept performance of perception.

At this point, we might ask, what would it be like to attend a Hotel Pro Forma performance? Firstly, Hotel Pro Forma challenges the expectations of conventional realist theatre. Instead, a number of slowly moving and sensuously saturated scenarios are staged that in various ways bring into play basic epistemological categories such as space, time, and transcendence. The staging affects the spectator's sensation and perception through the use of different media and medialities. Often, virtual technologies are involved (projection of digital video, use of audio effects, elaborate light designs), but the intermediality might just rely on the juxtaposition of real components (space/time/body). For example, in Why Does Night Come, Mother (1989), the spectators had their attention drawn to space and transcendence as epistemological categories, as they were placed on balconies from which theywith a dizzying feeling in the body-could look straight down at the performers, who were slowly alternating between standing, walking, gesturing, and lying on a floor deep below (Figure I). This way the spectators were engaged in an optical play between space and surface, between two and three dimensions as the performers in the lying position cancelled out the conventional experience of space and gravity. Seen against the white floor surface, they seemed to be in weightless fall. Hence, through the unconventional spectator perspective, the experience of everyday space was transcended. It created an unreal, dreamlike sensation of looking into eternity. The perceptual interplay of the medialities (space, time, body, and compositional stage image) took on a cognitive dimension as text, and voice added itself to the experience. Poems about longing and loss were sung and recited ceremoniously in the cathedral-like sounding, tall room.

Instead of playing dramatic roles, the performers in a Hotel Pro Forma production perform functions in the unfolding of stage images, choreographies, and soundscapes. The functions 


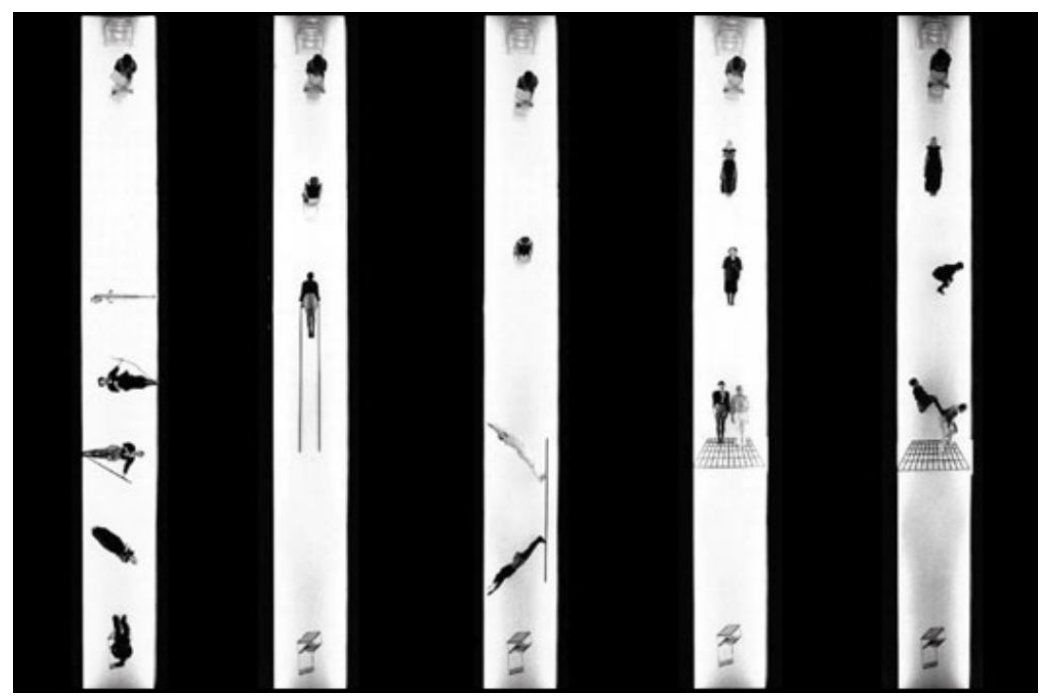

Figure 1. Montage of stage images from Why Does Night Come, Mother. Hotel Pro Forma, I989. Photo: Roberto Fortuna. Copyright: Hotel Pro Forma. License: CC-BY-NC-ND.

focus on their skills, history, or physiognomy, and what they may add to the entirety of the performance. Thus, the rowers' task in Navigare (1996) was to row an imaginary long-ship; the author Carsten Jensen's task in Chinese Compass (I998) was to recite a text by Carsten Jensen about his travel experiences in China; the task of performers of short stature in The Picture of Snow White (I994) was to just be dwarfs surrounding "Snow White" while framed by their own personal stories through a soundtrack. The insistence on presence, precision, and authenticity of the performer causes a reality effect that carries its own credibility.

The staging always refers to a theme, the choice of a fundamental phenomenon, for example, gravity, perspective, or the war, as a meaning-constituting frame for that which is staged. As semiosis the staging instigates an investigative mode, that is, a secondorder observation of the theme, whereby loose links between the stage signs and their interpretants are maintained. ${ }^{35}$ Assignment of meaning to the signs is disturbed and delayed. The spectator

${ }^{35}$ For an explanation of "dynamic interpretant," see Albert Atkin, "Peirce's Theory of Signs," in The Stanford Encyclopedia of Philosophy, ed. 
not only sees things for what they are, but also how they are what they are on stage. This second-order observation may be formulated as some concrete staging devices: ritualization, appropriation, and simple orchestration. These devices allow us to further connect Hotel Pro Forma's aesthetics with intermediality.

Ritualization means, in Max Weber's sense, that an action is no longer an action. The physical phenomenon, the act, has become detached from its intention, and the intention is postponed. In this way, the action is "meaningless" in that it has opened itself to a wealth of interpretations. ${ }^{36}$ As pointed out elsewhere, ritualization is also characteristic of the stylized and elevated acts in Hotel Pro Forma's performances. ${ }^{37}$ Dehlholm refers to these as "clenched actions." Unlike the ritual to which the myth offers an interpretation that decides the ritual's meaning, a Hotel Pro Forma performance postpones the meaning-making, in order for the spectator to make her own interpretation. A ritual is not performed, but ritualization is a qualitative characteristic of the staging. It means that the representation is an effect of the spectator's perception. For example, depending on the connections that one makes between the medial components space, body, image, and text in Why Does Night Come, Mother, it is possible to interpret the performers as dead souls in a white, weightless limbo. Ritualization in the performance reflects or mediates the spectator's process as the co-creator of meaning. ${ }^{38}$

Appropriation is related to ritualization: it also invites the spectator to realize the meaning. Appropriation means that found and non-manipulated materials, artefacts, people, and media

Edward N. Zalta (Summer 2013 Edition), accessed March 10, 2017, https: //plato.stanford.edu/archives/sum20 z/entries/peirce-semiotics/.

${ }^{36}$ Cf. Max Weber, "The Nature of Social Action," in Weber: Selections in Translation, ed. W. G. Runciman (Cambridge: Cambridge University Press, I99I). For a definition of ritualization, see Caroline Humphray and James Laidlaw, The Archetypical Actions of Ritual: A Theory of Ritual Illustrated by the Jain Rite of Worship (Oxford: Clarendon Press, I994), 73.

37 Cf. Kim Skjoldager-Nielsen, "Performance and Congregation: Experiential Metaphysics in Hotel Pro Forma's Operation: Orfeo and jesus_c_odd_size," Performance Research I 3:3 (2008): I68-169.

${ }^{38}$ Cf. Nibbelink and Merx's definition of intermediality as realized by the spectator. Nibbelink and Merx, "Presence and Perception," 220. 
technologies from the outside world are brought inside the frame of staging and made to play in the production of meaning. ${ }^{39} \mathrm{~A}$ sign's immediate interpretant is thereby transformed through a contextual interpretation. Just as Marcel Duchamp's readymades that turned from industrial product to art object, an inflatable plastic chair may be exalted, or the before-mentioned rower's special skill, rowing, is made into an art form, or the real-life dwarf doubles as one of Snow White's companions. Appropriation is generating material for the performance, and it initiates a conceptual reflection or second-order observation of what art and theatre are, how theatre is a hypermedium that may include all media and art forms, and how these potentially can be redefined. For example, opera becomes visual opera by bringing together the media voice, words, body, image, in a way that highlights visual art properties of the performance. When other media and art forms are creatively appropriated for the theatre hypermedium it is "remediation."

Finally, simple orchestration is a staging device that brings together media and art forms in the production of meaning. Components engage temporarily with one another in the unfolding of the performance's scenarios and structure. ${ }^{4 \circ}$ With Hotel Pro Forma it is montage of different opposable, incongruent or unexpected elements, cf. formalistic de-familiarization (ostranenie) or Eisenstein's montage of attraction. The simple orchestration is the device that directly facilitates intermediality. It is obtained by keeping the media and medialities-image, words, sounds, space, time, body, voice-separate from one another rather than letting them enter into a Gesamtkunstwerk in which all components are integrated in a homogeneous expression. In the mangaopera War Sum Up (20II), whose theme is war, large images in Japanese manga cartoon style of modern weapons systems, eyes, hands, explosions, etc., are projected on screens in front of and

39 Cf. appropriation art. For definitions of this art form, see Hal Foster, The Return of the Real (Cambridge: MIT Press, I996), I46; Sherri Irvin, "Appropriation and Authorship in Contemporary Art," British Journal of Aesthetics 45 (2005): I23-I37.

$4 \circ$ Cf. Ida Krøgholdt, "At blive performer hos Hotel Pro Forma," in Hotel Pro Forma, ed. Erik Exe Christoffersen (Aarhus: Klim, I998), I65. 


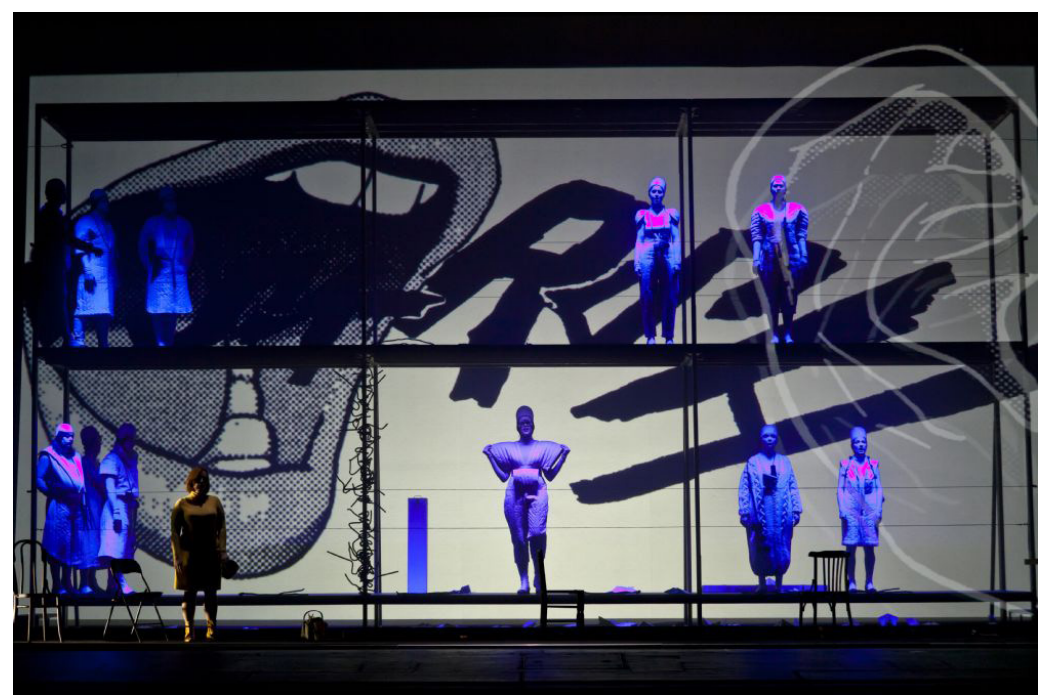

Figure 2. War Sum Up. Hotel Pro Forma, 20I I. Photo: Roberto Fortuna. Copyright: Hotel Pro Forma. License: CC-BY-NC-ND.

behind the stagnant opera singers posing on a scaffolding or on the proscenium (Figure 2).

The choir on the scaffolding is wearing white costumes, reminiscent of medieval warriors. A solo singer on the proscenium wears a similar but red costume and holds what looks like a spear. Opposite her another woman in a bright yellow modern business dress keeps an eye on what is happening on stage. By keeping the body at rest, focus is shifted to the voices and the song. But sung in Japanese, the words become incomprehensible to most of the audience. However, subtitles displayed on a screen above the stage means that the text's mediality is nonetheless highlighted: it becomes clear that the minimalistic acting on stage and manga images do not directly illustrate the text or vice versa. In fact, the libretto is composed of various texts from the Japanese Noh theatre and merely inspiration for performance's theme. The music, in playback, is stylistically a clash of newly composed symphonic music and what Hotel Pro Forma refers to as chamber- and electro-pop, and it works as affective backdrop for the scenarios. As a meaning-constituting structure, the performance is unfinished. 
Rather than exploring a text's dramatic dynamics, subjugating performance elements to the logics of narrative, causality, and psychology, while at the same time reducing the ambiguity of actions and meaning (bypotaxis), there is a theatrical dynamics in a Hotel Pro Forma production that correlates media and elements for their equality of signification (parataxis). In accordance with Irina Rajewsky, this means "each and every medial form of articulation occurs by right of its own materiality and contributes to the constitution and meaning-making of the entire product in each their individual way. Thus, intermediality is a communicativesemiotic concept based on the combination of at least two medial forms of articulation." "4I At the same time, meaning is contingent, uncertain, or the meaning that the spectator found by making connections between the various media and medialities of the performance could also have been different. Through perception, the spectator realizes a montage of signs and decides on an interpretation of what is seen. This is what simple orchestration as a staging device does to enable intermediality.

\section{Approaching Today's Cake is a Log}

We will now turn to the analysis of Hotel Pro Forma's exhibition. Before we embarked on our exploration in the first place, we were cued on what to expect and how to relate to the exhibits by Kirsten Dehlholm's presentation on Hotel Pro Forma's website: “Today's Cake is a Log is a performance, an exhibition, an attitude." ${ }^{42}$ Knowing Hotel Pro Forma's aesthetic strategy, these keywords reinforced our expectations: first, that the exhibition design would emphasize its performative feature-it even has the subtitle "a performative exhibition"; second, that it would mean the realization and affirmation of a certain attitude. What else could this attitude be than an assimilation of Hotel Pro Forma's

${ }^{41}$ Irina O. Rajewsky, "Intermediality, Intertextuality, and Remediation: A Literary Perspective on Intermediality," Intermédialités: Historie et théorie des arts, des lettres et des techniques 6 (2005): Io.

${ }^{42}$ Hotel Pro Forma, "Today's Cake is a Log," accessed I6 March 20I7, http://www.hotelproforma.dk/projects/todays-cake-is-a-log/. 
aesthetic strategy of looking at the world anew? As Dehlholm explains: "Today's Cake is a Log, the woman announced as she pushed her catering trolley through the Danish State Railwaystrain. It struck me how easily a few words can completely alter the meaning of everyday phenomena." 43

These curatorial notes by Dehlholm inspired us to adopt Mieke Bal's thinking on curatorial work for our analytical approach. Bal's concept "curatorial acts" suggests that the acts or performance of a visitor may to some degree be scripted by the curator's organization or staging of the exhibition, the presentation of objects before the gaze of the visitor asserting its influence on her behavior: "Like speech and the speech acts it generates, vision can be performative and produce acts of vision. Not only does looking have a performative potential, but showing, the primary act of curating, is specific in its impact upon exhibition visitors." 44 Bal's curatorial acts remind us of Maaike Bleeker's observation that " $[t]$ he theatre presents a staged version of the [spectator's] performance of perception." ${ }^{45}$ We suggest that the notion "performance of perception," with its self-reference and self-reflexivity, could serve to expand curatorial acts to include the whole human sensorial and perceptual apparatus, not merely sight, but also hearing, smelling, touch, proprioception, and kinesthesis, and thereby increase its calibration for the performative exhibition analysis. Obviously the exhibition visitor's situation is different from that of the theatre spectator: whereas the visitor is situated inside the exhibition environment and in close proximity to the artefacts, the spectator is (typically) placed outside (in front of and at distance from) the stage; and whereas the visitor is mobile, the spectator is (typically) seated. Compared to the distanced and fixated position of theatre spectator, the exhibition visitor's relative freedom to move about in space and spend time on the various exhibits might heighten her awareness of perception as performance, through the ways she navigates the environment, orients herself and relates

43 Hotel Pro Forma, “Today's Cake is a Log,” accessed I6 March 20I7, http://www.hotelproforma.dk/projects/todays-cake-is-a-log/.

44 Bal, "Curatorial Acts," I79.

45 Bleeker, "Corporeal Literacy," 38. 
to artefacts, and how she negotiates their different medialities and materialities. Thus, the visitor's performance of perception becomes conspicuous through its structurally related effects. We recall Bleeker's second concept "performance of performativity": "how perception actually produces what appears as the object of our perception." ${ }^{46}$

Our analytical approach is auto-ethnographical in the sense that we base it on our own experience of the exhibition's medialities and materialities. We want to understand the experiential potentiality of the exhibition as it is concretely created through its curation or staging. To paraphrase Nibbelink and Merx, we attempt to locate the intermedial both in the body and in the performance by observing ourselves through perceptual as well as a cognitive awareness. ${ }^{47}$ Instead of being spectators watching performers on the intermedial theatre stage, we enter the hypermedial space of the exhibition to become what Kattenbelt called "the player of the different media acting in the empty spaces between the media." 48

Seeing photographs from the exhibition on the website before our visit, our attention was caught by the incorporation of the different media; video, text, props, set design, installation, as well as performers (image, body, voice) who originate in or refer to the past performances. They appeared to become remediated through the exhibition: a new intermedial feature. This prospect prompted us to formulate a series of analytical questions. How are the media redefined by their new setting? What kind of experiential potential is created by the way these objects are presented and by their different medialities and materialities? How is one addressed by the objects? How may one inspect them? What actions and associations do they prompt? To which extent does prior knowledge about Hotel Pro Forma affect the experience? And finally, does the exhibition succeed in transferring the aesthetic strategy of Hotel Pro Forma?

\footnotetext{
${ }_{46}$ Bleeker, "Corporeal Literacy," 38.

47 Bleeker, "Corporeal Literacy," 38.

$4^{8}$ Kattenbelt, "Intermediality in Theatre and Performance," 23.
} 


\section{Performing the Exhibition ${ }^{49}$}

At the foot of the staircase to the exhibition halls we pass the wardrobe (Figure 3). We are not invited to leave our coats there, the rag is already full of clothes: shiny, colourful, and metallicvery eye-catching. At closer look, it turns out that the suits are made of wrapping materials, empty candy and sugar packaging with Japanese and Danish characters and logos. This brings to mind the familiarity of everyday objects (suits) but with an unexpected twist (the material they are made of). This is a remediation in the sense Bolter and Grusin suggest, as "that which remediates $[\ldots]$ appropriates the techniques, forms, and social significance of other media to rival or refashion them in the name of the real." ${ }_{50}$ In a sense, we are faced with a double remediation that changes the social significance of media: first, the wrapping materials are removed from their social context and redefined in the artistic context of the original performance, reappearing as suits; second, the costumes are removed from the theatre stage to reappear in the performative exhibition. Only en passant we notice the discreet text plaque that let us know that Annette Meyer designed the suits for the performance Monkey Business Class (1996), suggesting that this information is of lesser importance. Significant, however, are the artefacts in their extraordinary materiality and the perceptual and cognitive engagement they offer. Accessible as the suits are, we are tempted to try them on, but museum etiquette kept us from doing so. Yet, already through the proximity of the artefacts and our self-observation we were implemented as performers in the exhibition.

On the first floor our awareness of being performers is increased as we enter the first exhibition room and are greeted by our own reflections (Figure 4). A large dressing mirror is placed in front of the entrance. On a chair next to the mirror sits a lady, knitting. At first, it is difficult to tell if she is just a museum custodian or

${ }_{49}$ Another version of the analysis appeared in Kim Skjoldager-Nielsen and Daria Kubiak, "Hotel Pro Forma. Dagens kage er en træstamme," review of the exhibition, Peripeti 25 (2016).

5o Bolter and Grusin, Remediation, 65. 


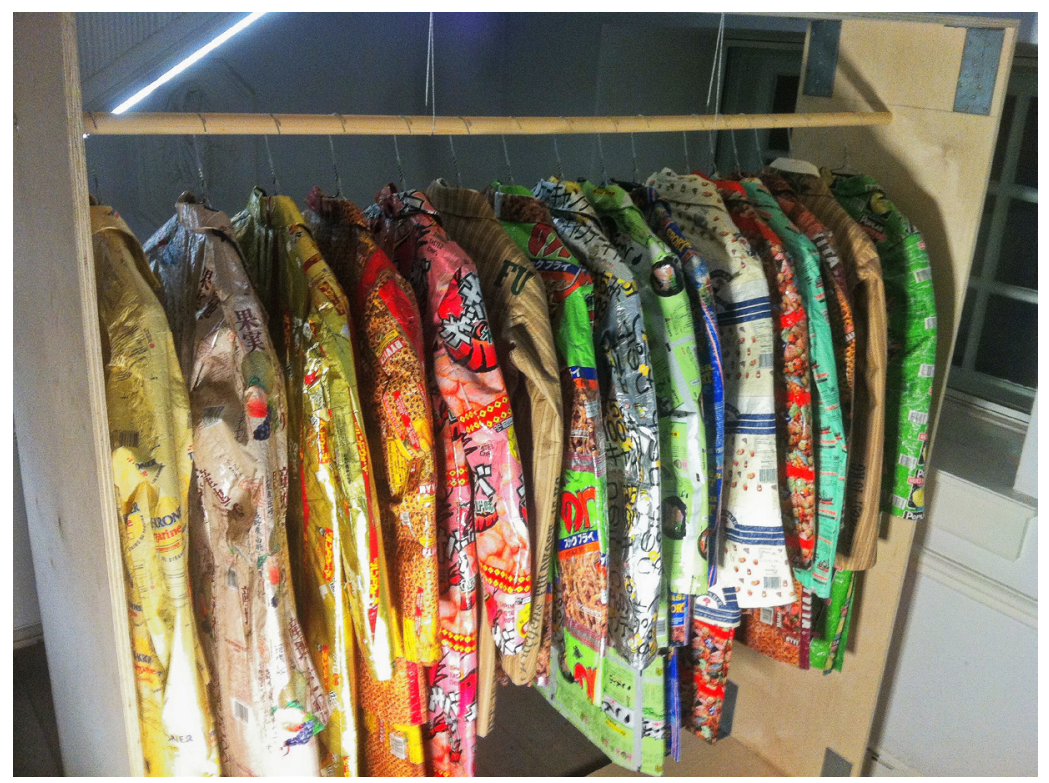

Figure 3. Clothes rag, Today's Cake is a Log. Hotel Pro Forma, 2015. Photo: Daria Skjoldager-Nielsen. Copyright: Hotel Pro Forma. License: CC-BY-NC-ND.

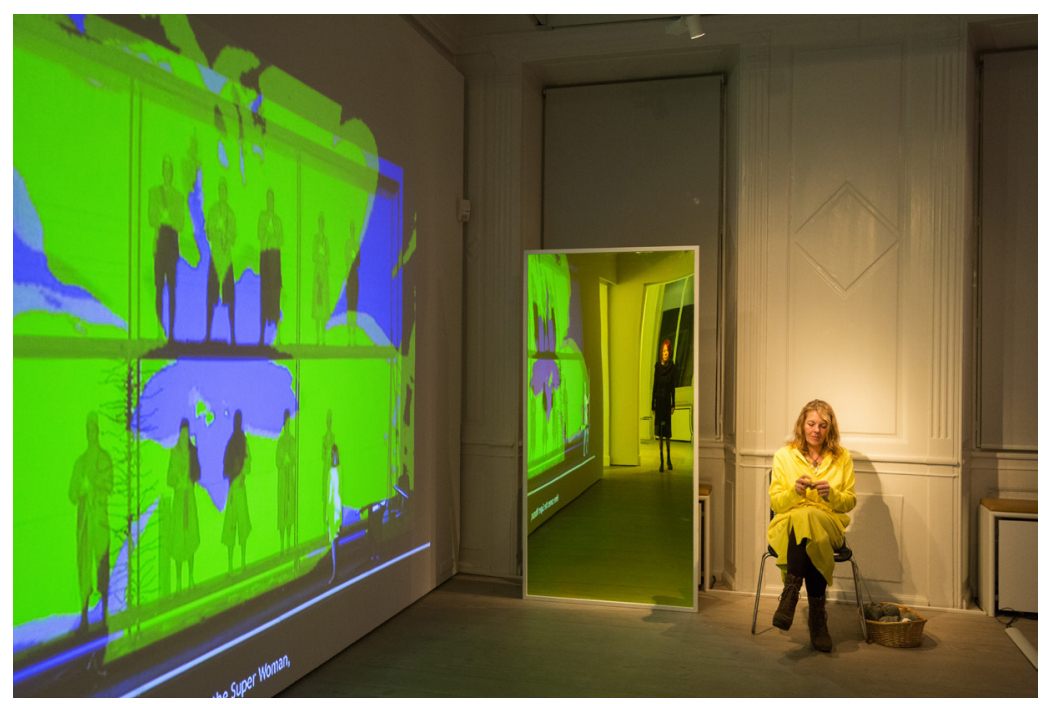

Figure 4. Mirror room, Today's Cake is a Log. Hotel Pro Forma, 20I 5. Photo: Torben Eskerud. Copyright: Hotel Pro Forma. License: CC-BY-NC-ND. 
if Dehlholm has placed her there as a performer. She notices our and other visitors' presence in the room. She greets us with a smile and goes back to knitting. Her bright yellow business dress, however, is almost too extraordinary for a museum custodian, and we assume that she is a performer. She sits in between two large screens covering opposite walls. On the screens we see video images of medieval warrior-like figures standing on scaffolding with Japanese manga-style backdrops. The small plaque on the wall explains that the video presents the opera War Sum Up (20I I). There is no sound. To hear what turns out to be opera music and singing, you have to take a seat on the benches in the center of the room and put on headphones. Here the performance's intermediality is subtly mirrored in the exhibit's use of technology initially keeping image, voice, music, and body apart, its simple orchestration only possible for the visitor to realize by sitting down and putting on the headset. The visitor is faced with the choice to literally become the player acting in the empty spaces between media. If she chooses to do so, in a sense, she momentarily reacquires the theatre spectator's position. If she dwells and looks carefully enough, she may notice that the lady sitting on the proscenium in the video is knitting and wearing the exact same yellow dress as the lady in the chair in the exhibition room. The doubling of the lady in the video makes the artwork reach across time and space. The knitting lady is both part of the performance on the screens and the observer of visitors' performance. The visitor is at the same time observing and being observed, thus reaffirmed as a co-performer of the exhibition.

In the next room large white paper rolls of printed text are hanging from the ceiling all-along the wall (Figure 5). The texts are from the performances and are arranged into collages. Through the materiality of the rolls, the words used by Hotel Pro Forma are made tangible (we may actually manipulate the rolls and read more of the texts) and give the impression of a theatre that is not only visual. In a sense, the rolls of text seem to cascade off the wall as a waterfall of words that flows into the room. What is more, you may manipulate the paper and create folds by the way it settles onto the floor. Thereby we play with the texts and make different parts of text come together in the formation of 


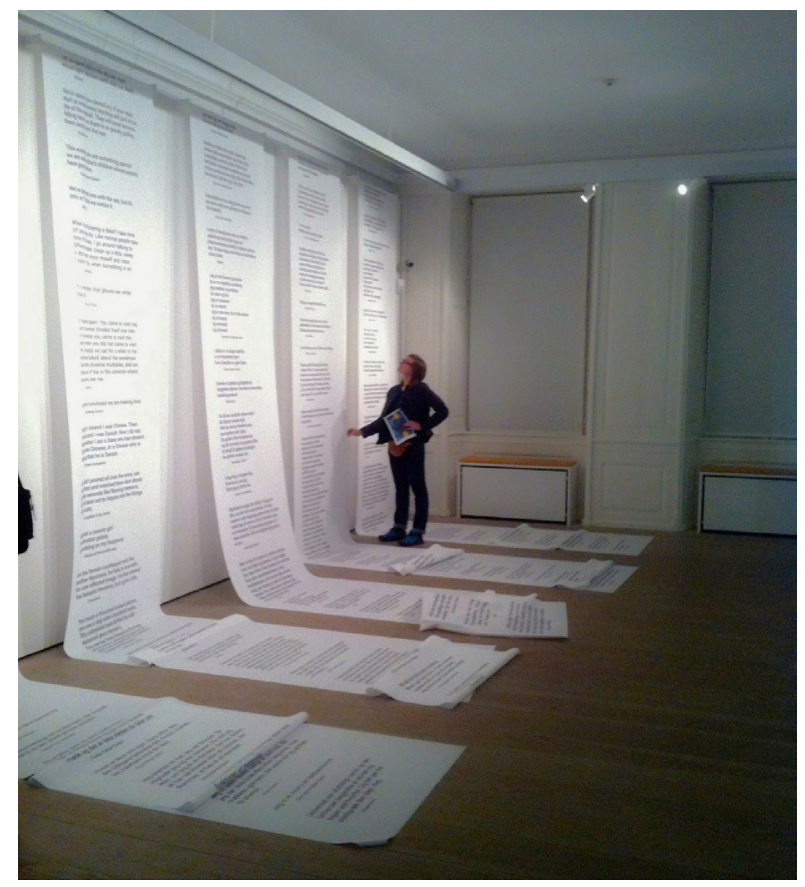

Figure 5. Text collages, Today's Cake is a Log. Hotel Pro Forma, 20I 5. Photo: Kim Skjoldager-Nielsen. Copyright: Hotel Pro Forma. License: CC-BY-NC-ND.

new texts. Our playful displacement of the texts in space enacts once again the staging device of simple orchestration, while at the same time, the text medium of the performances is remediated as a social artefact to engage the visitors.

Another installation in the same room consists of set design that extends through the doorway into the next room. A total overview is impossible. Seen from its end, the series of illuminated Plexiglas plates with coloured motifs seem to depict a continuous landscape. In order to see them all, one has to walk along the installation. If one does that, one will find that the motifs do not constitute one large continuous image, but are composed of individual parts not really matching each other. The installation plays with vision and perspective. It is not important that the set design was used in I Only Appear to be Dead (2005) or how it was used there; remediated by the exhibition space, it stages a playing with 


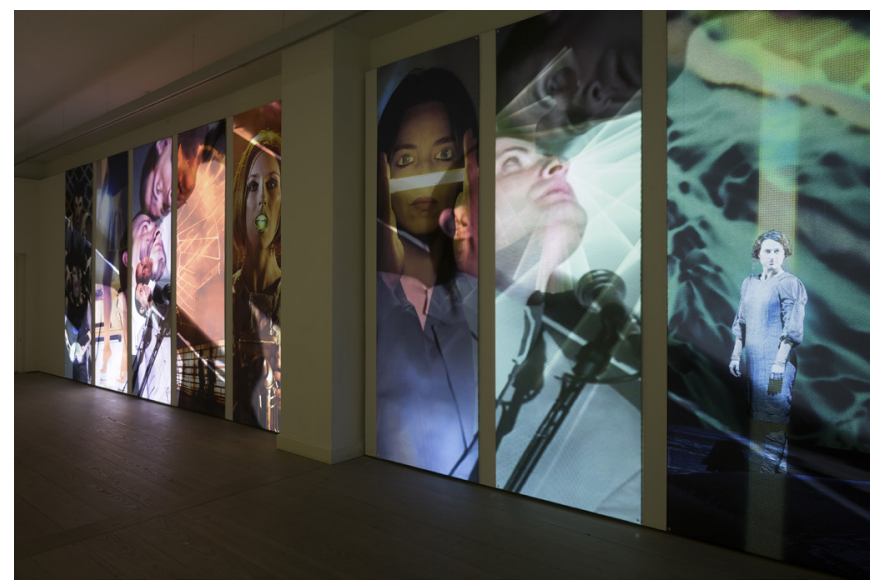

Figure 6. Photo/video montage, Today's Cake is a Log. Hotel Pro Forma, 2OI 5. Photo: Torben Eskerud. Copyright: Hotel Pro Forma. License: CC-BY-NC-ND.

the point of view. The contingency of perspective that Hotel Pro Forma explores is hinted at through the embodied perspective of the visitor and her possibility to shift it.

Contingency as an effect is further demonstrated by means of simple orchestration in another installation, which uses images from different performances. Videos are projected onto still photographs in a way that creates unforeseen and unexpected montages of performances and actors (Figure 6). Faces and bodies are distorted and the installation creates deformed or temporal overlapping between different performances. To experience and appreciate this intermediality, you have to watch it for quite a while, pointing to Hotel Pro Forma's investigations of time as an epistemological basic category.

The artefacts activate us through their mediality, materiality, and placement; there are no descriptions of the exhibits and no explanations are provided, as would usually be the case in a museum. We have to behave like explorers, driven by curiosity in order to experience and attribute meaning to the objects-not unlike the engaged spectator in the theatre, except for our mobility. One installation is almost hidden and reveals itself only to the one who delves into the exhibition (Figure 7). Plexiglas covers 


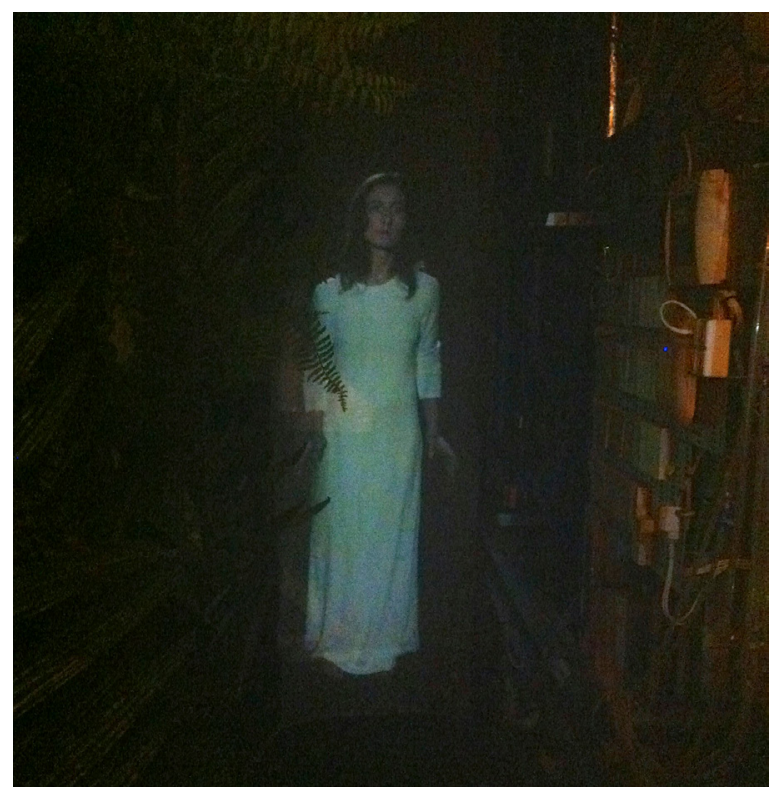

Figure 7. The ghost, Today's Cake is a Log. Hotel Pro Forma, 2015. Photo: Daria Skjoldager-Nielsen. Copyright: Hotel Pro Forma. License: CC-BY-NC-ND.

the opening of a narrow crevice in the wall. One of the inside walls is covered by green plants and ferns and the other one by humming machines; medialities of life and lifelessness confronting each other. At first this contrast grabs the attention, but the main clue of the installation is yet to be revealed. A thin woman dressed in white is hidden deep in that space. She stares at us and stretches her hands as if she wanted to be held or rescued from this strange space. She is scarily beautiful and seems very real. Only a close look reveals that she is in fact a video projection on a loose canvas waving in a slight breeze. She is a ghost, caught between life and death. The display has no plaque referring to any performance; but the experience it creates is reminiscent of Hotel Pro Forma's work with visual illusion, whether produced by technology or mere perspective (as in the 1989 Why Does Night Come, Mother).

While climbing the stairs to the next floor a voice captures our attention. When we get there we see a young woman with loose, 


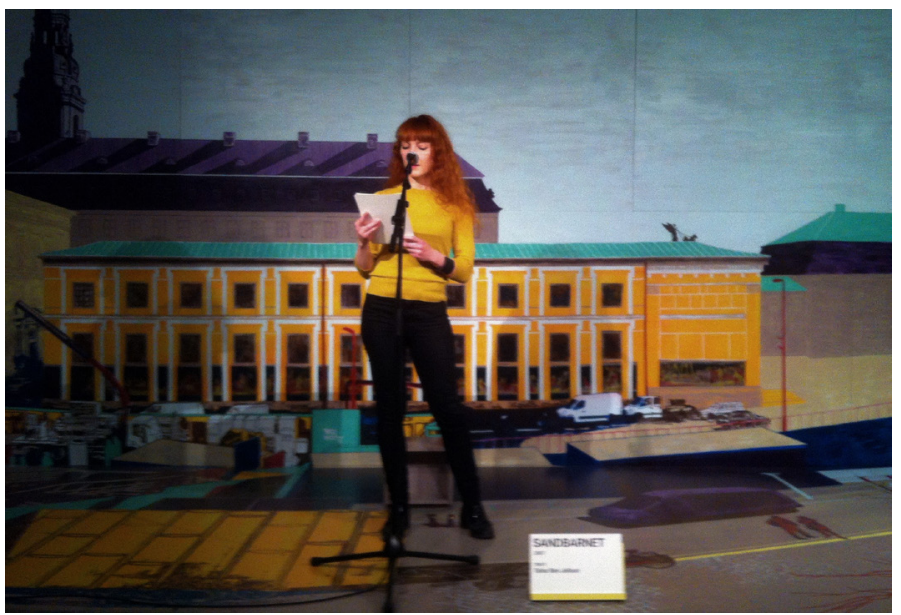

Figure 8. Readhead reader, Today's Cake is a Log. Hotel Pro Forma, 2015. Photo: Daria Skjoldager-Nielsen. Copyright: Hotel Pro Forma. License: CC-BY-NC-ND.

flaming red hair (Figure 8). She stands by a microphone against a painted background depicting the cityscape outside, behind the very same wall: the parliament building Christiansborg, the traffic in the street, and the ongoing metro construction. The painting covers the entire wall and part of the floor, suggesting that she belongs to the other world, the world of the artworks. She makes eye contact with us but, busy reading a text, she does not greet us. A sign stands on the floor with the title "The Sand Child / 2007 / Text / Tahar Ben Jelloun" indicating the performance whose text she is reading and the author of that text. She is sharing the story with the listener, but at the same time she is observing the audience sitting and standing in front of her. Dressed in her private clothes, she could be just anyone from the audience, as if anyone could take her place. Only those who know Hotel Pro Forma's works very well will recognize her as one of their performers, but again that is of no real importance. The sense that any of the visitors could replace her is important, as it points to appropriation as a staging device applied to the performers, who often retain an authenticity whether it is through their appearance, skill, or known history. 


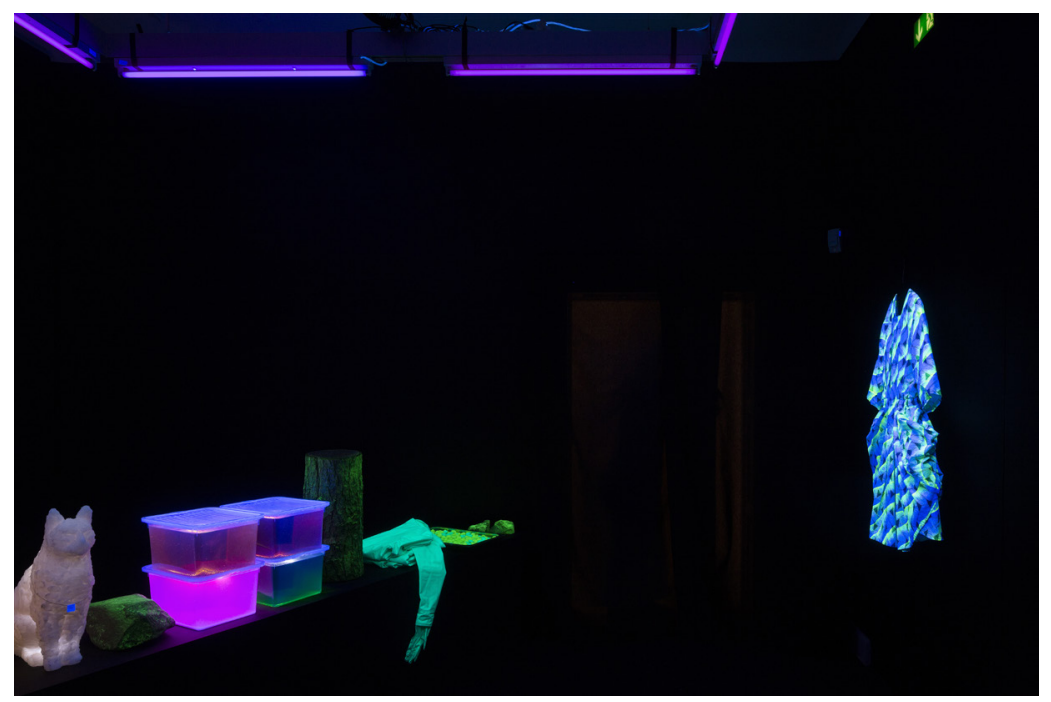

Figure 9. UV room, Today's Cake is a Log. Hotel Pro Forma, 20I 5. Photo: Torben Eskerud. Copyright: Hotel Pro Forma. License: CC-BY-NC-ND.

The final room presents a collection of props from the performance The One Who Whispers (2012) (Figure 9). On a table stand, among other things, are semi-transparent plastic boxes, like the ones used at home for storage. They are filled with colourful jelly. Next to them there are some kitschy plastic cats that could have been brought home as souvenirs or given away as hate gifts. They are ordinary found objects, appropriated for the performance/exhibition. A blue-and-green striped dress hangs on the wall, spread out like a fan. Suddenly the light in the room changes to UV light. Everything is transformed: the dress, the cats, and the boxes. They glow as if lit with a fire from within. It works as a kind of remediation using light: the artefacts are the exact same ones but now seen through the medium of UV. The glow affects the visitor in a strange way. Our sensation of the objects is heightened. It is-as the Danish philosopher Dorthe Jørgensen would say-as if one is out of oneself (Greek ek-stasis) to truly see the objects, liberated from their everyday intentionality, as if they were ritualized. The objects and the visitor simply co-exist in this moment without any other concern. It 
is a liberating moment that can bring joy. It is an experience of beauty in that it has no other purpose and carries a value of its own. ${ }^{51}$ This part of the exhibition may be recognized as an extract of Hotel Pro Forma's performative aesthetics: to stage the visitor's sensation not merely to titillate but to stimulate reflection on what it means to be in this world-to look at the world anew. A world where nature, the people, the arts, everything, much too often becomes subject to some agenda rather than left to be valued by what they are in themselves.

\section{Conclusion}

True to her own project, Kirsten Dehlholm did not celebrate Hotel Pro Forma's thirty years by creating a retrospective with documentation of works ordered in accordance with their place in the company's history. Rather, she created an insight intoor metaphorically in line with the title: a cross-section of-Hotel Pro Forma's aesthetics in the form of a brand-new exhibition, distributed across, altogether, eight rooms on two floors: a work of works, or rather, a remediation for the exhibition hypermedium of artefacts, texts, fragments of images, video, and audio selected from the performances as well as new staging in the form of live performance readings. In this sense of hypermediacy, by bringing together animate and inanimate material in one and the same space, the exhibition repeats theatre's all-inclusiveness towards other art forms and media defined by Kattenbelt. This hypermediacy is further foregrounded as the visitors enter into the perceptual interplay with both exhibits and the present performers, creating the visitors' conspicuous self-awareness of becoming performers themselves. Navigating through different rooms and exhibits and negotiating their presentation of media and materialities, the visitors create their own narratives and understanding of Hotel Pro Forma's intermedial aesthetics. This aesthetics is transferred from the stage to the exhibition, and realised by the visitor

${ }^{51}$ Dorthe Jørgensen, Skønhed: En engel gik forbi (Aarhus: Aarhus Universitetsforlag, 2006), 7. 
as performer, physically acting the in-between of media and realising the intermediality of the exhibition.

We refer to remediation as a creative strategy as we see the exhibition appropriating "techniques, forms, and social significance of other media to refashion them in the name of the real." ${ }_{52}$ Here the aim of the remediation is to transfer the intermedial experience of Hotel Pro Forma's aesthetic strategy, as it was produced in the performances, to the exhibition, and through this experiential paradigm, in a very real sense, transform the theatre spectator into a performer of the exhibition. This is achieved to the extent the visitor's intermedial experience is created through surprises and confusions, the deconstruction of perceptual expectations, as Nibbelink and Merx describe it - the intent here seemingly being the achievement of resensibilization through second-order observation, or awareness of perception.

Only then does it make sense that the exhibition offered no explanations, but left one to one's own senses. No system by which to navigate was presented. The text plaques next to exhibits referred only to title and production year of the performance. The chronology and history were not established and therefore of no importance. Instead our attention was subtly directed to the experiential potential of artefacts/media in their interplay with space and visitor. This seemed the only curatorial concern: to let the visitor engage and reflect on her own, the theme, Hotel Pro Forma's aesthetic strategy, only hinted at by the title Today's Cake is a Log and Dehlholm's curatorial notes.

This intention might not have occurred to every visitor. However, what was required was exploration and play with the possibilities offered by medialities and materialities of the exhibits, that is, to become the performer of perception as suggested by the exhibition. Only if one was willing to do so could the experiential transferal, the effect or performativity of perception, succeed.

${ }_{52}$ Bolter and Grusin, Remediation, 65. 


\section{References}

Bal, Mieke. "Curatorial Acts." Journal of Curatorial Studies, vol. I, no. 2, (20I2): I79-I92.

Bay-Cheng, Sarah, Chiel Kattenbelt, Andy Lavender, and Robin Nelson, eds. Mapping Intermediality in Performance. Amsterdam: Amsterdam University Press, 2010.

Bolter, Jay David, and Richard Grusin, Remediation: Understanding New Media. Cambridge: MIT Press, I999.

Chapple, Freda, and Chiel Kattenbelt, eds. Intermediality in Theatre and Performance. Amsterdam and New York: Rodopi, 2006.

Christoffersen, Erik Exe. “Den u-selvfølgelige sansning.” In Skønhedens Hotel: Hotel Pro Forma: Et laboratorium for scenekunst, edited by Erik Exe Christoffersen and Kathrine Winkelhorn, I9-45. Aarhus: Aarhus Universitetsforlag, 20I 5 .

Christoffersen, Erik Exe, and Kathrine Winkelhorn, eds. Skønhedens Hotel: Hotel Pro Forma: Et laboratorium for scenekunst. Aarhus: Aarhus Universitetforlag, 2015.

Crawford, Lawrence. "Viktor Shklovskij: Différance in Defamiliarization." Comparative Literature 36 (I984): 209-2I9.

Foster, Hal. The Return of the Real. Cambridge: MIT Press, I996.

Humphray, Caroline, and James Laidlaw. The Archetypical Actions of Ritual: A Theory of Ritual Illustrated by the Jain Rite of Worship. Oxford: Clarendon Press, I994.

Ingemann, Bruno, "Den besøgende: Social identitet, læring og oplevelse - en metodisk diskussion." In Udstillinger mellem focus \& flimmer, edited by Elisabeth Bodin and Johanna Lassenius, 85-Io9. Copenhagen: Multivers, 2006.

Irvin, Sherri. "Appropriation and Authorship in Contemporary Art." British Journal of Aesthetics 45 (2005): I23-I37.

Jørgensen, Dorthe. Skønhed: En engel gik forbi. Aarhus: Aarhus Universitetsforlag, 2006.

Kattenbelt, Chiel. "Intermediality in Theatre and Performance: Definitions, Perceptions and Medial Relationships." Culture, Language and Representation, vol. VI (2008): 19-29. 
Kattenbelt, Chiel. "Theatre as the Art of the Performer and the Stage of Intermediality." In Intermediality in Theatre and Performance, edited by Freda Chapple and Chiel Kattenbelt, 29-40. Amsterdam and New York: Rodopi, 2006.

Krøgholdt, Ida. “At blive performer hos Hotel Pro Forma.” In Hotel Pro Forma, edited by Erik Exe Christoffersen, I 53-I68. Aarhus: Klim, 1998.

Lehmann, Hans-Thies. Postdramatic Theatre. Translated by Karen Jürs-Munby. London and New York: Routledge, 2006.

Nibbelink, Lisbeth Groot, and Sigrid Merx. "Presence and Perception: Analysing Intermediality in Performance.” In Mapping Intermediality in Performance, edited by Sarah Bay-Cheng, Chiel Kattenbelt, Andy Lavender, and Robin Nelson, 218-229. Amsterdam: Amsterdam University Press, 20 Io.

Noë, Alva. Action in Perception. Cambridge: MIT Press, 2004.

Qvortrup, Lars. "Hotel Pro Forma: Laboratorium for æstetiske undersøgelser." Peripeti 25 (2016): 84-98.

Rajewsky, Irina O. "Intermediality, Intertextuality, and Remediation: A Literary Perspective on Intermediality." Intermédialités: Historie et théorie des arts, des lettres et des techniques 6 (2005): 43-64.

Schechner, Richard. "Performance Studies: The Broad Spectrum Approach.” In The Performance Studies Reader, edited by Henry Bial, 7-9. New York: Routledge, 2004.

Skjoldager-Nielsen, Kim. "Performance and Congregation: Experiential Metaphysics in Hotel Pro Forma's Operation: Orfeo and jesus_c odd_size." Performance Research I3:3 (2008): I63-I75.

Skjoldager-Nielsen, Kim, and Daria Kubiak. "Hotel Pro Forma: Dagens kage er en træstamme." Peripeti 25 (2016): I42-I46.

Theil, Per, Kirsten Dehlholm, and Lars Qvortrup. Hotel Pro Forma: The Double Staging: Space and Performance. Copenhagen: Arkitektens Forlag, 2003.

Wagner, Meike. "Of other Bodies: The Intermedial Gaze in Theatre.” In Intermediality in Theatre and Performance, edited by Freda Chapple and Chiel Kattenbelt, I25-136. Amsterdam and New York: Rodopi, 2006. 
Weber, Max. "The Nature of Social Action.” In Weber: Selections in Translation, edited by W. G. Runciman, 7-32. Cambridge: Cambridge University Press, I99I.

Winkelhorn, Katherine. "Et blik ind i Hotel Pro Formas kunstneriske praksis.” In Skønhedens Hotel: Hotel Pro Forma: Et laboratorium for scenekunst, edited by Erik Exe Christoffersen and Kathrine Winkelhorn, 213-225. Aarhus: Aarhus Universitetsforlag, 2015.

\section{Websites}

The Stanford Encyclopedia of Philosophy. "Peirce's Theory of Signs." Accessed March IO, 20I7. https: //plato.stanford.edu/archives/ sum20I3/entries/peirce-semiotics/.

Victoria \& Albert Museum. "Curtain Up: Celebrating 40 Years of Theatre in London and New York." Accessed April I2, 2017. https://www.vam.ac.uk/exhibitions/curtain-up-celebrating-40years-of-theatre-in-london-and-new-york.

Peripeti. "Remediering mellem film og teater - en kreativ strategi." Accessed April I 2, 20I 7. http://www.peripeti.dk/2009/06/03/265/.

Hotel Pro Forma. “Today's Cake is a Log.” Accessed March I 6, 20 I 7. http://www.hotelproforma.dk/projects/todays-cake-is-a-log/. 
